\title{
Expert opinion
}

\section{'Problems with Managed Psychiatric Care without a Psychiatric Manager'}

\author{
(JOSEPH WeSTERMEYER [1991] Hospital and Community Psychiatry, 12, 1221-1224)
}

Stories of mishap and disaster have a grisly if reluctantly acknowledged appeal. Who can resist flicking through the annual reports of the medical defence organisations or reading the epitomes of the Health Ombudsman? What newspaper editor with an eye for the circulation figures omits tales of human misfortune?

Professor Westermeyer's anecdotes are no exception to this general rule. However, for psychiatrists plotting (and plotting) their way through the various organisational changes in the NHS in general, and in the psychiatric services in particular, they are stories with a moral.

To the cis-Atlantic reader some of the terms may be unfamiliar, but the picture which emerges is clear enough. Professor Westermeyer, drawing on his clinical, medico-legal and administrative experience, describes instances of serious blunders arising in "managed psychiatric care" in which a nonpsychiatrist controls the care given, occasionally (in these cases) using a psychiatrist as little more than a purveyor of medicines. ("Psychiatrist Psychopharmacology Consultant"). "Managed care" is a system of service delivery which "attempts to balance access, quality and costs" (Scharfstein, 1990), in ways which are predictably contentious. The "problems" arising stem from decisions made by those ill-qualified to do so, from inadequate assessment and treatment, from the scant regard paid to the 'doctor-patient relationship' and from considerations of cost taking precedence over clinical necessity. They are highlighted in his description of seven "critical cases" involving the management of people with severe affective disorders, five of whom committed suicide, one of whom sustained serious physical injury and one of whom was denied necessary treatment. The management plans and how they were arrived at are outlined.

The points raised are of considerable interest to those psychiatrists concerned with working relationships in community mental health teams and who, through constant attrition, may be in indecision over the role and responsibilities of consultant psychiatrists, to those who have managerial responsibilities, and to those devising and nurturing programmes of medical and clinical audit.

Professor Westermeyer's detractors might question how representative such 'problems' in managed care without a psychiatrist-manager are, and point to the peripheral involvement of psychiatrists in several of the cases described. The riposte to point one would be that it is perhaps better that if blunders are to be made they be made by those qualified to do so and, to point two, responsibility is necessarily linked with authority.

Those who take the trouble to read the article may conclude that it is rather like the cautionary tales of Hilaire Belloc without the malefactors having received their come-uppance. However, it seems, in the way things are described, that the structure of the system exerts a major influence over the decision making and, therefore, the outcome, i.e. "organisations are beginning to dominate the structure, process and outcome of medical care" (Burchell et al, 1988). It presents a strong argument for the clear delineation of roles of the members of psychiatric teams and for the introduction of rigorous audit systems in psychiatric management and finally, reasserts the value to the individual patient of the "personal service of the consultant" (Sims, 1991.)

Consultant Psychiatrist

North Wales Hospital

Denbigh, Clwyd LL16 5SS

NeIl S. Da VIES

\section{References}

BURCHELl, R. et al (1988) Physicians and the organisational evolution of medicine. Journal of the American Medical Association, 260, 826-831.

SCHARFSTEIN, S. S. (1990) Utilisation management: managed or mangled psychiatric care? American Journal of Psychiatry, 147, 965-966.

Sims, A. C. P. (1991) Even better service: a psychiatric perspective. British Medical Journal, 302, 1061-1063. 